\title{
The Dunning-Krueger effect in Neurosurgery
}

\author{
"The fool doth think he is wise, but the wise man knows himself to be a fool." \\ - William Shakespeare
}

Dr Yam Bahadur Roka

MS, M.Ch., IFAANS

Senior Consultant and Head

Department of Neurosurgery

Neuro Cardio and MultiSpeciality hospital, Biratnagar, Nepal

dryamroka@yahoo.com

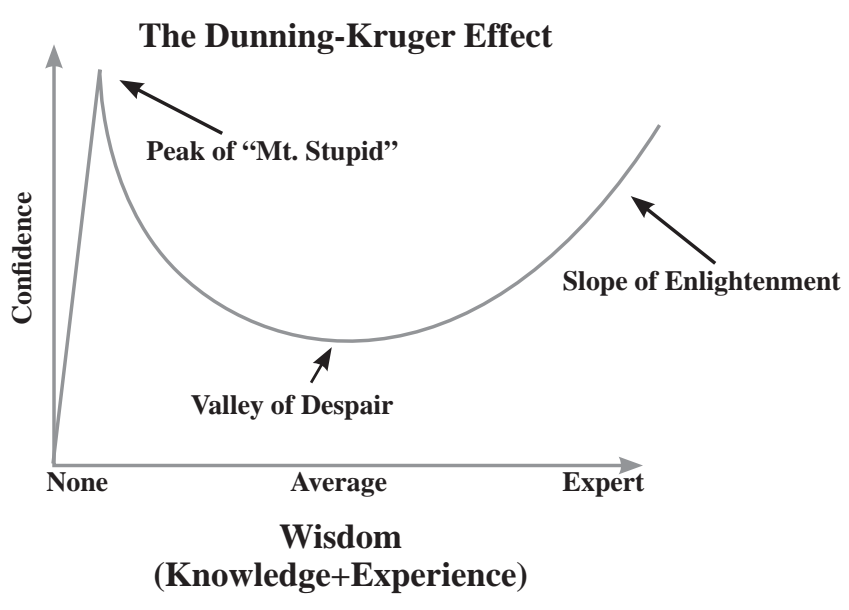

Figure 1: the DK effect showing the peak of confidence in the people with least wisdom and low confidence in the experts. ${ }^{6}$

This study gave the example of a certain robber of a bank who was caught through the surveillance camera and had the perception that rubbing lemon juice on his face could make him invisible to the camera. They then tested their hypothesis on undergraduate psychology students and found that those who scored the least had high overestimation of themselves and those that score the highest underestimated their competence.

The DK effect is rampant in today's world and effects all organizations be it medical or non- medical., ${ }^{2,3}$ This is a cognitive bias with greater perception of their cognitive ability leading to a superiority complex without selfawareness. It has been wrongly associated with "stupid" and low IQ. Classically this leads to high confidence in those with less experience and low confidence in those with expertise. The unskilled do not realize their shortcomings, are not aware of complications, have limited knowledge, do not introspect and thus are highly confident in their decisions. With this limited perspective they seem to be highly skilled, experts and thus give their suggestions whenever needed or not. The experts having seen, known, studied and experienced are aware of the shortcomings, their capabilities, know that each complication cannot be dealt with, believe in the limitations of medical sciences, have seen unexpected results and thus have low estimate of them. 
Thus during the beginning of a career we may be very confident of our training, knowledge, expertise and thus may attempt to do major surgeries and when failed will give various reasons, proof, suggestions to show that the procedure or decision or technique was rightly done. Later as we become senior with our experience and knowledge, we go with caution, think twice before surgery, areslow/ deliberate, and always ask or doubt ourselves of the decisions realizing that medical science is vast. We may be always seen in doubt or low confidence, even though the results are the best.

\section{How to reduce the DK effect:}

The DK effect affects all of us. We as humans are limited to our knowledge and thus are deficient in the knowledge of many fields. Although we are experts in one area, we may be a novice in other subjects and thus all humans are susceptible to this syndrome. The best neurosurgeon in the world may be the worst musician or writer or poet. Yet within ones subject one must be aware of the knowledge, the shortcomings, personal ability, judgement skills, experience and exposure to avoid falling to the DK effect. Some ways to reduce DK effect are by (adapted) 5

\section{Do not assume:}

keep yourself updated and read more which will show the real depth of the subject and will prevent you assuming that you are the expert.

\section{Take feedback:}

always take feedback from your colleagues, juniors, seniors and other people around to know your performance. Take criticism wisely and improve on your deficits.

\section{Be inquisitive:}

always question your decision and confirm by reading, asking, discussions so that you give the best advice or do the best treatment.

Finally it easy to see the DK effect in others but not in oneself, so it is imperative that one first rules out this effect personally before looking for it in others.

\section{References:}

1. Kruger J, Dunning D. Unskilled and unaware of it: How difficulties in recognizing one's own incompetence lead to inflated self-assessments. Journal of Personality and Social Psychology7 (6):1121-1134, 1999

2. Krueger J, Mueller RA (2002). Unskilled, unaware, or both? The better-than-average heuristic and statistical regression predict errors in estimates of own performance. Journal of personality and social psychology 82: 2;180-8, 2002

3. Burson KA, Larrick RP, Klayman J. Skilled or unskilled, but still unaware of it: how perceptions of difficulty drive miscalibration in relative comparisons. Journal of personality and social psychology90 (1): 60-77, 2006

4. http://www.talyarkoni.org/blog/2010/07/07/Whatthe-Dunning-Kruger-effect-Is-and-Isnt/. Accessed July 2018

5. https://www.verywellmind.com/an-overview-of-thedunning-kruger-effect-4160740. Accessed July 2019

6. https://www.instazu.com/tag/dunningkrugereffect. Accessed July 2019. 